\title{
Treatment of Community-Acquired Pneumonia: Are All Countries Treating Children in the Same Way? A Literature Review
}

\author{
Daniele Donà, ${ }^{1}$ Dora Luise, ${ }^{1}$ Liviana Da Dalt, ${ }^{2}$ and Carlo Giaquinto ${ }^{1}$ \\ ${ }^{1}$ Pediatric Infectious Diseases Division, Department for Woman and Child Health, University of Padua, Padua, Italy \\ ${ }^{2}$ Pediatric Emergency Department, Department for Woman and Child Health, University of Padua, Padua, Italy
}

Correspondence should be addressed to Dora Luise; luise.dora@gmail.com

Received 16 June 2017; Accepted 8 October 2017; Published 6 November 2017

Academic Editor: Alessandro Mussa

Copyright (C) 2017 Daniele Donà et al. This is an open access article distributed under the Creative Commons Attribution License, which permits unrestricted use, distribution, and reproduction in any medium, provided the original work is properly cited.

\begin{abstract}
Background. Pneumonia represents an important threat to children's health in both developed and developing countries. In the last 10 years, many national and international guidelines on the treatment of pediatric CAP have been published, in order to optimize the prescription of antibiotics and limit their cost and side effects. However, the practical implementation of these guidelines is still limited. Main Text. We analyzed the current recommendations for the therapy of pediatric community-acquired pneumonia (CAP) that all converge on the identification of aminopenicillins and beta-lactams as the optimal treatment for CAP. We also conducted a review of the current literature on antibiotic regimens used for pediatric CAP to identify the current state of guidelines implementation in different settings. We selected 37 studies published from 2010 to 2016, including both retrospective and prospective studies, mainly cross-sectional and hospital based. The results show a global heterogeneity in the antibiotics prescription for pediatric CAP, with application of guidelines varying from $0 \%$ to more than $91 \%$ and with important differences even within the same country. Conclusions. Our review has demonstrated that the implementation of the guidelines is still limited but also that achieving the optimal prescription is possible and can be done in both developed and developing countries.
\end{abstract}

\section{Introduction}

Pneumonia is the single greatest cause of death in children worldwide, with an estimated 1.3 million deaths in 2011 and more than $90 \%$ occurring in developing countries [1-3]. It is responsible for $4 \%$ of deaths in newborns and $14 \%$ of deaths in pediatric patients [4]. The incidence of CAP is lower in developed countries: in the US it is about $35-40 / 1000 /$ personyears in children $<5$ years old, 20/1000 person-years in children 5-10 years old, and 10/1000 person-years in children $>10$ years old. Despite this, approximately $50 \%$ of children with CAP $<5$ years old, $20 \%$ between $5-10$ years old, and $10 \%$ of children $>10$ years old need to be hospitalized [5]. These numbers demonstrate the burden that CAP represents for society and for economic healthcare resources.

\section{Materials and Methods}

In the first part of the study, we compared the latest national and international guidelines on pediatric CAP, including all those who were published since 2005 to 2016, focusing on their recommendations for first-line therapies.

Then we performed a search on PubMed and Scopus databases, looking for studies published from 2010 to 2016 about CAP antimicrobial therapy in children, trying to get data from as many different countries as possible. We also performed hand-search of references of relevant articles. Our search included both retrospective and prospective studies, mainly cross-sectional and hospital based, including both inpatients and outpatients. All of them except for one [6] included pediatric patients only.

To get a more extensive review of CAP prescribing behavior, for those countries where specific studies on antimicrobial prescriptions for CAP were not available, a search for articles on antimicrobial prescriptions in pediatric age groups was performed. All articles including CAP as reason for treatment were included. 


\section{Results and Discussion}

3.1. Different Countries, Same Pathogens. Organisms responsible for CAP vary stratifying children by age because of the developing immune system and age-related exposures: viruses or mixed infections are more common amongst younger patients (children under 5 years of age), while exclusive bacterial origin and atypical etiology (mainly Mycoplasma pneumoniae and Chlamydophila pneumoniae) are more often identified in older children $[7,8]$. S. pneumoniae and Haemophilus influenzae are the commonest bacterial pathogens isolated in children under five years with CAP accounting for $30 \%-50 \%$ and $10 \%-30 \%$, respectively [9]. Around $50 \%$ of deaths due to pneumonia are attributable to these organisms [10].

Viral etiology has been documented in up to $80 \%$ of CAP cases in children younger than 2 years and much less in older children (10-16 years). The most frequently identified viral pathogen in younger children is Respiratory Syncytial Virus (RSV), rarely detected in older children. Less frequent are Adenoviruses, Bocavirus, Human Metapneumovirus, Influenza $A$ and $B$ Viruses, Parainfluenza Viruses, Coronaviruses, and Rhinovirus. Up to $33 \%$ of hospitalized children are simultaneously infected by 2 or more viruses. Mixed infections (both of viral and bacterial etiology) have been documented in $2-50 \%$ of children with CAP, more frequently in inpatients, which are more seriously ill than outpatients $[3,11]$.

Atypical pneumonia caused by different pathogens is characterized by a different clinical course: slowly progressing, with malaise, sore throat, low-grade fever, and cough developing over 3-5 days. The main organisms responsible for atypical pneumonia are M. pneumoniae in older children and $C$. pneumoniae in infants. Legionella species are rarely identified in children $[8,12,13]$.

The etiologic definition is difficult for many reasons, such as low yield of blood cultures, difficulty in obtaining adequate sputum specimens from younger children, frequent specimen contaminations by upper airways bacterial flora and invasiveness of pulmonary biopsy, lung aspiration, and bronchoalveolar lavage which are rarely performed [13]. However, over the last 10 years, there have been improvements in PCR techniques for viral identification on nasopharyngeal aspirates or secretion, and molecular assays are now commonly used in Europe and in the US.

Vaccines are the most effective strategy for prevention of pediatric CAP. Haemophilus influenzae type B (HiB) conjugate vaccine and 7-valent pneumococcal conjugate vaccines (PCV7) dramatically decreased the incidence of bacterial CAP after introduction of universal vaccination campaigns $[14,15]$. PCVs have been included for some years in the immunization schedules of children in their first year of life in many countries and they have completely modified the burden of pneumococcal diseases among these children and their unvaccinated contacts of any age [16]. Currently, the polyvalent pneumococcal vaccine (PCV13) confers immunity to approximately $85 \%$ of serotypes responsible for most invasive pneumococcal diseases [17].
3.2. Same Pathogens, Same Treatment: International CAP Recommendations. Since its introduction during the 20th century, antibiotic therapy, along with vaccines, has decreased CAP mortality of $97 \%$ in developed countries [14]. Most of the time the choice of an antimicrobial agent is empirical and based on the most common etiologies for each age group, on the local prevalence of causative organisms, and on the presence of risk factors for atypical or resistant bacteria [18].

During the last 10 years, many guidelines have defined the best antimicrobial regimen for CAP in children considering spectrum of activity, antimicrobial susceptibility, tolerability, bioavailability, safety, and cost $[19,20]$. As already highlighted by other authors, these guidelines present some differences in treatment strategies, but almost all agree on the first-line therapy to administer in case of CAP (Figure 1) [19].

For infants $<2$ months of age, the association with ampicillin and aminoglycosides is the most suggested therapy, ensuring coverage for Group B streptococci and Gramnegatives. In case of atypical pneumonia, in this period of life, because of the possibility of Chlamydia trachomatis infection, macrolides are recommended [3, 19, 21-23].

For all children $>3$ months of age, the narrowest regimen with $S$. pneumoniae activity is suggested worldwide. Penicillin is the ideal first-line therapy, being a narrow-spectrum agent achieving therapeutic concentrations for S. pneumoniae in the lung up to MIC of $4 \mathrm{mg} / \mathrm{ml}$ [24]. However, due to its limited bioavailability, oral amoxicillin is reported as an equivalent and more feasible option [24, 25].

Despite general agreement on the agent, differences in dose and posology have been reported, varying according to pneumococcal resistance [19]. Indeed, beta-lactam effectiveness is time dependent and S. pneumoniae does not develop resistance through $\beta$-lactamase enzyme production, but through the alteration of the cell wall's antimicrobial targets (penicillin-binding proteins) [26]. Thus, in the setting of resistant $S$. pneumoniae serotype, higher concentration at the infection site is needed in order to saturate penicillinbinding proteins and to overcome resistance [27].

A study of children with pulmonary pneumococcal infection [28] provided data to develop a model for describing amoxicillin pharmacokinetics administered with different patterns: $50 \mathrm{mg} / \mathrm{kg} /$ day in two or three administrations daily. The resulting curve, integrated with $S$. pneumoniae MIC for amoxicillin, showed that, for intermediate resistant $S$. pneumoniae (MIC $4 \mathrm{mg} / \mathrm{ml}$ ) CAP, the amoxicillin plasma concentration remained above the pneumococcal MIC level for about 4 hours. Therefore, amoxicillin administered every 8 hours maintains blood and lung concentrations that are above S. pneumoniae MIC for enough time to allow $S$. pneumoniae eradication. A longer interval between administrations (every 12 hours), in case of intermediate resistant serotypes, would not permit having a sufficient antimicrobial plasma concentration [28]. Similarly, penicillin G needs more frequent administrations than other beta-lactams, because of its shorter half-life [13].

Beta-lactam dose is the other key factor for pathogen eradication. Through the different guidelines, amoxicillin daily dose varies from $40-50 \mathrm{mg} / \mathrm{kg}$ to $90-100 \mathrm{mg} / \mathrm{kg}$, with higher dosage recommended in areas with higher risk for 


\begin{tabular}{lc} 
& \\
& \\
\hline AGE & World Health Organization \\
& First-line therapy \\
\hline $0-2$ months & Ampicillin iv and \\
& aminoglycoside iv \\
pneumonia & Cotrimoxazole po/ \\
$>2$ months severe pneumonia & amoxillin po \\
$>2$ months very severe & Benzylpenicillin im or iv \\
pneumonia & Ampicillin iv and \\
\hline
\end{tabular}

\begin{tabular}{lc}
\hline & \\
\hline AGE & $\begin{array}{c}\text { Italian Paediatric Society } \\
\text { First-line therapy }\end{array}$ \\
\hline $0-1$ months & $\begin{array}{c}\text { Ampicillin iv and } \\
\text { aminoglycoside iv } \\
\text { Amoxicillin po/ampicillin iv } \\
3 \text { months to } 5 \text { years }\end{array}$ \\
5-15 years & $\begin{array}{l}\text { Amoxicillin po/ampicillin iv } \\
\text { Amoxicillin po/ampicillin iv or } \\
\text { macrolide if suspect atypical } \\
\text { pneumonia }\end{array}$ \\
\hline
\end{tabular}
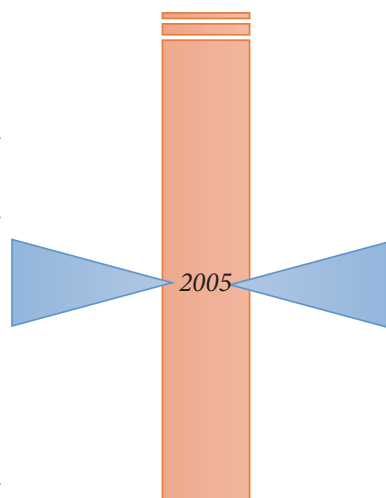

South African Thoracic Society

AGE

First-line therapy

0-2 months

Ampicillin/penicillin iv and aminoglycoside iv Amoxicillin po high

3 months to 5 years dose/ampicillin iv high dose

$>5$ years

Amoxicillin po high dose/ampicillin iv high dose

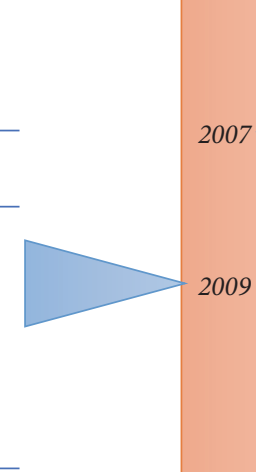

\begin{tabular}{|c|c|}
\hline \multicolumn{2}{|c|}{ Taiwan Paediatric Working Group } \\
\hline AGE & First-line therapy \\
\hline $0-1$ months & $\begin{array}{l}\text { Ampicillin iv and } \\
\text { aminoglycoside iv }\end{array}$ \\
\hline
\end{tabular}

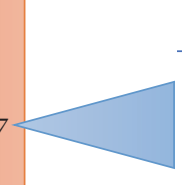

2 months to 1 year

Amoxicillin-clavulanate/ penicillin/ampicillin/ ampicillin sulbactam

Amoxicillin-clavulanate/

2-5 years penicillin/ampicillin/ ampicillin sulbactam \pm macrolide

6-18 years Penicillin \pm macrolide

India Clinical Epidemiology Network Task Force on
Pneumonia
AGE

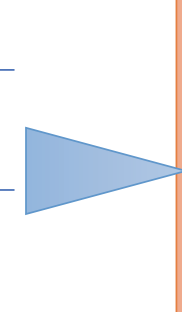

Paediatric Infectious Disease Society Infectious Disease Society of America

\begin{tabular}{lc} 
AGE & First-line therapy \\
\hline$<5$ years outpatients & Amoxicillin po \\
$>5$ years outpatients & Amoxicillin po \\
Inpatients fully immunized & Ampicillin iv/penicillin G iv \\
Inpatients not fully immunized & Cefotaxime/ceftriaxone iv \\
\hline
\end{tabular}

\begin{tabular}{lc}
\hline \multicolumn{2}{c}{ Asociacion Espanola de Pediatria de Atencion Primaria } \\
AGE & First-line therapy \\
\hline 3 month to 5 years not fully immunized & $\begin{array}{c}\text { Amoxicillin- } \\
\text { clavulanate po }\end{array}$ \\
3 months to 5 years fully immunized & Amoxicillin po \\
$5-18$ years typical pneumonia & $\begin{array}{c}\text { Amoxicillin po } \\
\text { Azithromycin po/ } \\
\text { clarithromycin po }\end{array}$ \\
5-18 years atypical pneumonia & $\begin{array}{c}\text { Amoxicillin po + } \\
\text { macrolide po }\end{array}$ \\
\hline
\end{tabular}
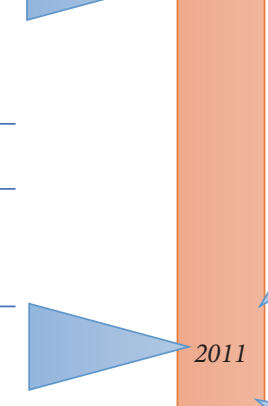

2011

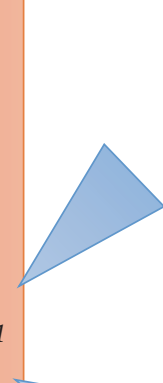

Canadian Pa
AGE
pneumonia
pneumsevere

$>3$ months, severe pneumonia

First-line therapy

Amoxicillin po high dose/ampicillin iv

Ceftriaxone im or iv/

cefotaxime iv and clarithromycin po

clarithromycin po

British Thoracic Society
First-line therapy

Nonsevere pneumonia Amoxicillin po

Amoxicillin po/ cefuroxime iv/ cefotaxime iv/ ceftriaxone iv \pm

Severe pneumonia macrolide

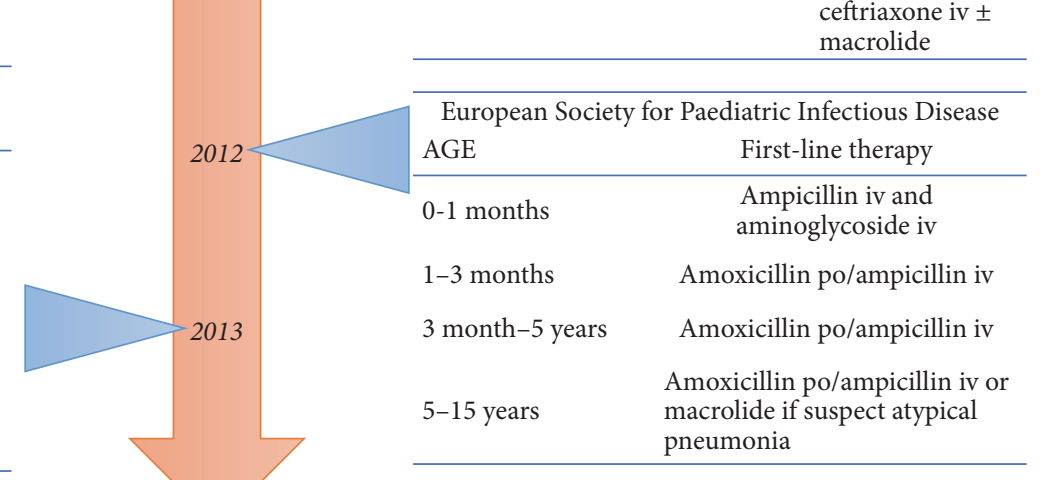

Figure 1: Pediatric CAP guidelines timeline [adapted by Berti et al., 2013 [19]]. 
antibiotic-resistant serotype, as in the US [13, 19]. In the same way, for inpatient parenteral therapy, higher doses of penicillin G or ampicillin are recommended [13].

The only two guidelines which suggest an aminopenicillin plus beta-lactamase inhibitor as first line are the Taiwan Pediatric Working Group and Asociacion Espanola de Pediatria de Atencion Primaria [29, 30]. Unlike the first one, in which aminopenicillin plus beta-lactamase inhibitor (e.g., amoxicillin-clavulanate) is suggested as first-line therapy for all children treated as outpatient, the Spanish guidelines recommend coamoxiclav only for children who are not fully immunized with conjugate vaccines for type $\mathrm{B} H$. influenzae and for S. pneumoniae. Indeed, this population is at increased risk to develop a CAP by aggressive $S$. pneumoniae serotypes and other less common organisms, as $H$. influenza. Unlike Pneumococcus, type B and nontypeable $H$. influenzae became resistant to penicillin through the production of $\beta$-lactamase. Therefore, treatment with the association of amoxicillin with a $\beta$-lactamase inhibitor ensures a broader coverage [30]. It should be noted that the addition of a $\beta$ lactamase inhibitor does not change the amoxicillin kinetic curve; as a consequence, in order to treat a pneumococcal infection with the association of amoxicillin with clavulanate, the therapy should be administered every 8 hours [26].

The WHO guidelines are the only one suggesting cotrimoxazole as alternative to amoxicillin in outpatient treatment. This recommendation derived from evidence of no difference in treatment failure rates between amoxicillin and cotrimoxazole [31-33]. Despite concerns about the increase of $S$. pneumoniae and $H$. influenzae resistant to cotrimoxazole, as demonstrated by some authors [34], the reason for this indication is mainly attributable to economic factors. Indeed, for children $<10 \mathrm{~kg}$, the cost of a five-day treatment with amoxicillin is higher than the same duration on cotrimoxazole [35-37].

No guidelines recommend oral cephalosporins as firstline therapy. Indeed, pharmacokinetic and pharmacodynamic studies showed that none of the available oral cephalosporins is able to exceed the pneumococcal MIC for more than $50 \%$ of the time between two administrations [26]. Moreover, recent US data on S. pneumoniae susceptibility to cefdinir and cefuroxime indicated only $70 \%$ to $80 \%$ efficacy, compared with $84 \%$ to $92 \%$ amoxicillin efficacy $[38,39]$.

The only cephalosporin that has been demonstrated superior to penicillin in S. pneumoniae eradication, even if resistant, is ceftriaxone [40]. No microbiologic failures have been reported for $S$. pneumoniae with ceftriaxone MIC of $4.0 \mathrm{mg} / \mathrm{mL}[13,41]$. Thus, ceftriaxone or cefotaxime in standard doses is suggested by all guidelines as alternatives in case of first-line treatment failure, severe clinical conditions, or not fully immunized children [3, 7, 13, 21-23, 29, 30, 41].

Due to high prevalence of macrolide resistance circulating strains of $S$. pneumoniae, macrolides are not recommended as empiric therapy for CAP. Their use is suggested only when atypical etiology is suspected or in case of persistence of symptoms despite beta-lactams administration $[7,13$, 42]. This strict indication for macrolides use derives from the evidence that Mycoplasma lower respiratory tract infection (LRTI) has a high rate of spontaneous clinical remission and the use of azithromycin has been associated with the selection of resistant organisms because of its prolonged serum elimination half-life [13]. Moreover, no significant benefits of antibiotic treatment in M. pneumonia infection have been documented [37].

For complicated pneumonia (i.e., moderate parapneumonic effusion and necrotizing pneumonia), antimicrobial therapy must be broadened to cover less common but highly aggressive pathogens as Streptococcus pyogenes and S. aureus. As for S. pneumoniae, macrolides cannot be considered an effective empiric therapy because of the high level of resistance [13].

Despite the fact that no penicillin or cephalosporin resistance has been reported for $S$. pyogenes, some authors suggest that, in case of concomitant symptoms attributable to toxic shock syndrome, combination therapy with clindamycin decreases the severity of symptoms [43]. In fact, since clindamycin inhibits protein synthesis (by binding the 50 S subunit of the bacterial ribosome), it inhibits the production of $S$. aureus toxins, resulting in a lower inflammatory reaction. Clindamycin may be bacteriostatic or bactericidal depending on the organism and drug concentration and is indicated by US guidelines as a good option for both methicillin susceptible $S$. aureus (MSSA) and communityacquired methicillin-resistant $S$. aureus (CA-MRSA) strains [13].

Nowadays almost all MSSA have penicillin resistance which can be overcome with the addition of a $\beta$-lactamase inhibitor or through penicillinase-resistant beta-lactams, such as oxacillin or first-generation cephalosporins. MRSA strains have mecA gene that encodes penicillin-binding protein $2 \mathrm{a}$, an enzyme that has low affinity for beta-lactams, leading to resistance to all antibiotics active against MSSA. During the last decade, both community-associated and hospitalacquired infections with MRSA have increased. MRSA, accounting for $20 \%-40 \%$ of all hospital-acquired pneumonia (HAP) and ventilator-associated pneumonia (VAP), have demonstrated a rapid increase as cause of pneumonia even in patients without exposure to the healthcare system [44]. This CA-MRSA has become an important cause of CAP complicated by empyema and necrosis [45].

Since erythromycin resistance predicts inducible clindamycin resistance in many isolates, a $D$-test to assess clindamycin susceptibility should always be performed. In case of $D$-test positivity, the use of clindamycin should be avoided, since it is highly possible that the organism will become resistant during the infectious process, especially in high-inoculum infections such as empyema [45]. On the other hand, all CA-MRSA strains are susceptible to vancomycin, which is considered by all guidelines as the drug of choice if MRSA is suspected [7, 13]. Although linezolid has been recently demonstrated as efficient as vancomycin for the treatment of MRSA pneumonia, its use should be considered as a second-line treatment for cost consideration (linezolid costs $>10$ times more than vancomycin) and because linezolid-resistant MRSA has already been described $[46,47]$. 

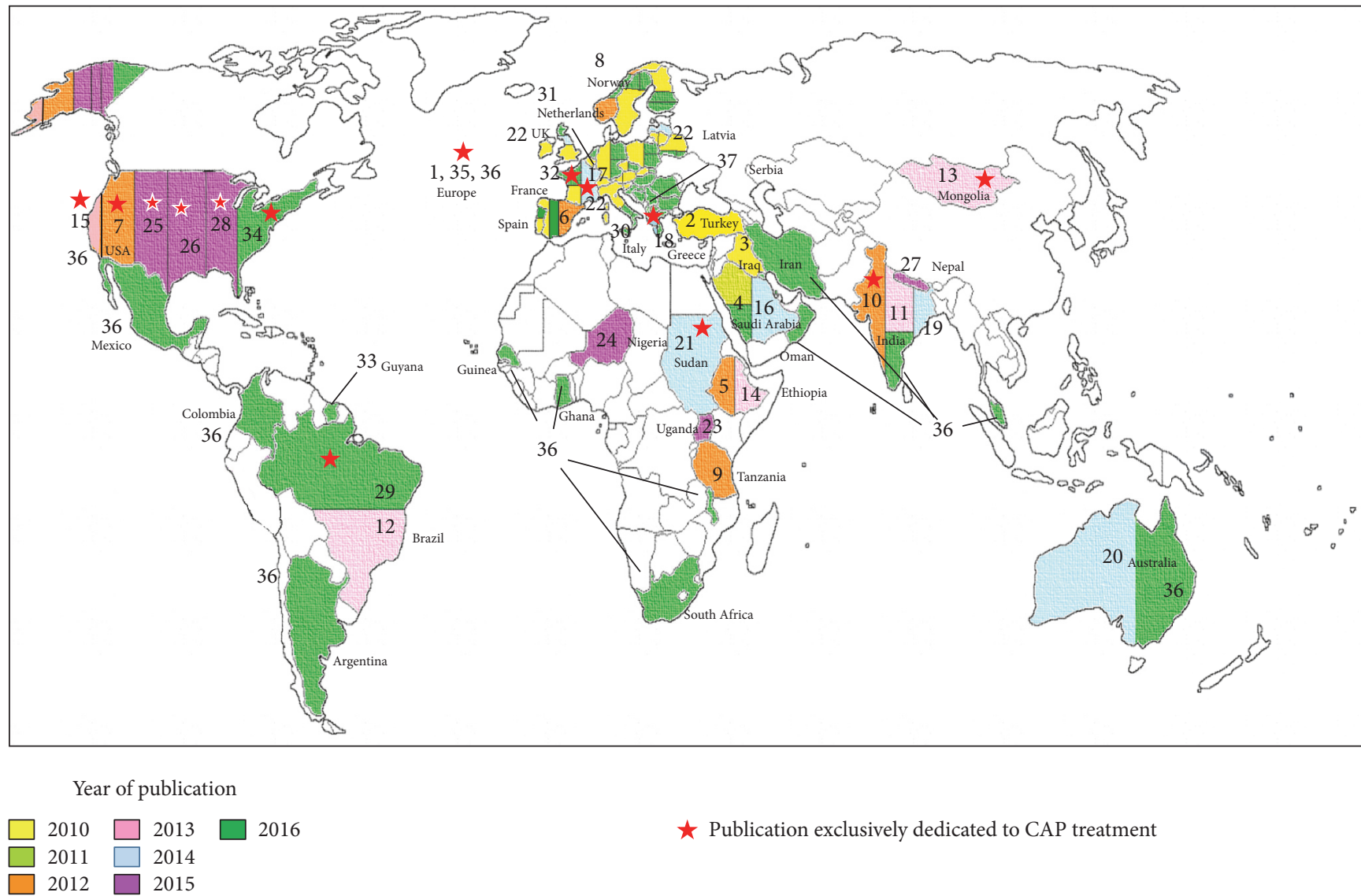

FIGURE 2: World map of papers on CAP treatment in children stratified by year of publication.

3.3. Different Countries, Same Treatment? A worldwide review about CAP antimicrobial therapy in children includes 37 studies about antibiotics prescriptions in 50 countries published since 2010. The results are shown in Table 1 and Figure 2. Even if the studies were different in design and study population, their results give a good picture of the antibiotic prescription patterns in different environments, and they show the global heterogeneity in the application of the guidelines for the treatment of childhood pneumonia.

In fact, the first important result of our review is that the correct implementation of the guidelines is not confined to specific areas but may be variable even inside the same country. For example, Iroh Tam et al., through a 2-year retrospective study on hospitalized children with CAP in six US centres, showed that the most used antibiotics were thirdgeneration cephalosporins (73\%), and only $1 \%$ of the patients received amoxicillin. These findings during the first 2 years after US guidelines publication led the authors to recommend more strategies for educating healthcare providers [71]. On the other hand, Thomson et al. in another retrospective study set in an US hospital, with the same population (hospitalized children between 3 months old and 18 years old) in a 15month period (May 2011-July 2012), had an opposite result, reporting that $63,6 \%$ of the pediatric CAP were treated with aminopenicillins and only $16.8 \%$ with third-generation cephalosporins [80].
We found a similar situation comparing studies from France $[63,78]$ and India $[57,65]$.

Interestingly, in France our data about CAP prescriptions derive from two different settings. Launay and colleagues investigated antimicrobial prescriptions and recommendations adherence in a French Emergency Pediatrics Department through a prospective two-period study, including all children aged one month to 15 years. The results were encouraging, with an increase of recommendation compliance from $18.8 \%$ to $48 \%$ between 2009 and 2012, and a consequent increase of amoxicillin monotherapy prescription from $54.2 \%$ to $71 \%$ [78]. Dubos et al., on the other hand, give us a picture of CAP antimicrobial prescriptions through general practitioners (GPs), private pediatricians, and pediatric fellows. The results of the standardized questionnaire submitted to every participant showed that CAP guidelines were insufficiently followed, with high rate of amoxicillin/clavulanate prescriptions (amoxicillin in monotherapy was prescribed in only $29 \%$ of cases, for $54 \%$ of cases associated with clavulanic acid) [63].

In India, in addition, we found some of the lowest rates of prescription on aminopenicillins as single therapy. Choudry and Bezbaruah, in a prospective observational study based in a university hospital in Assam, including inpatients up to 12 years, reported $0 \%$ use of penicillin as single therapy in cases of pediatric pneumonia. The therapy mostly used (54\% 


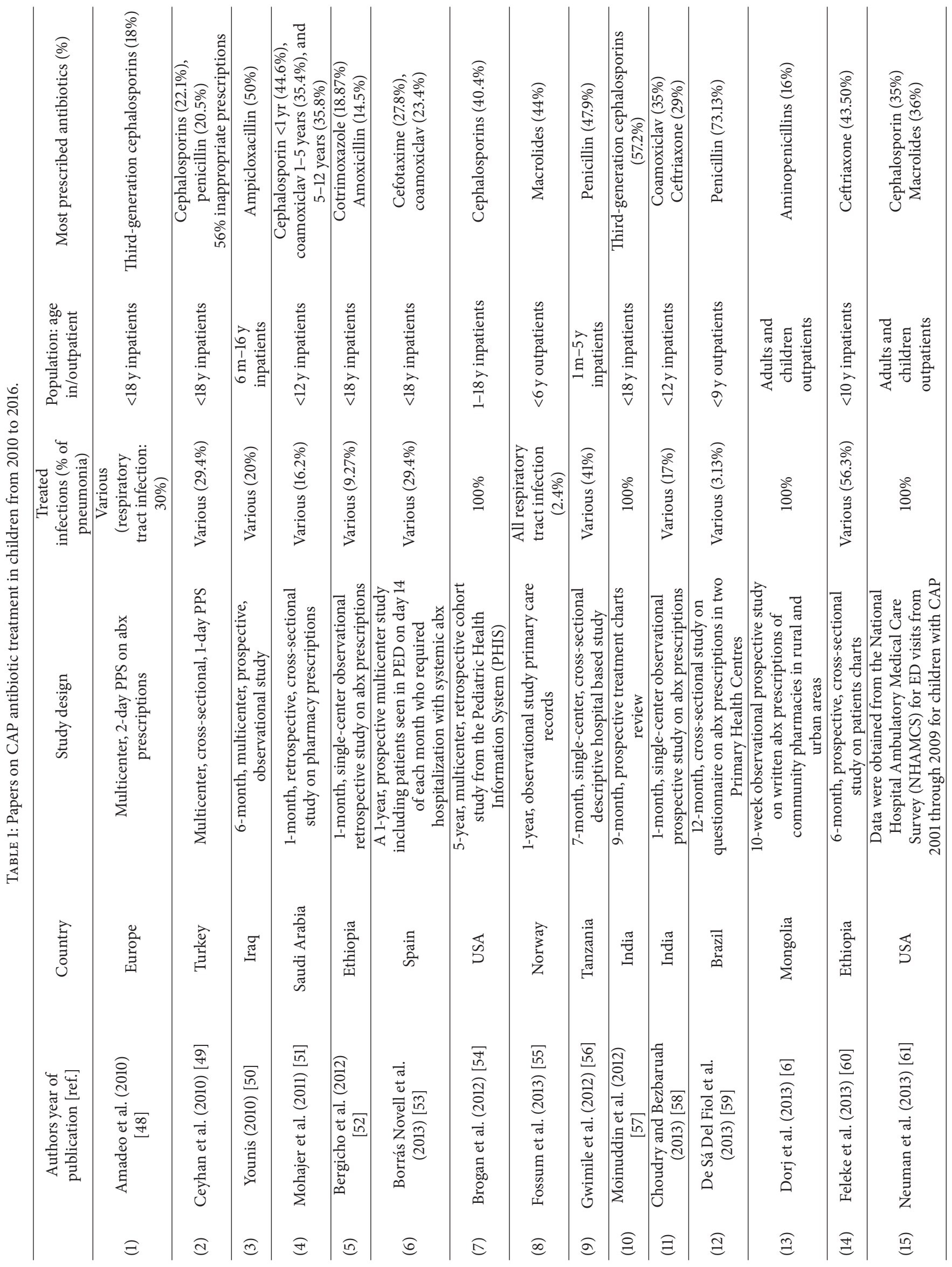




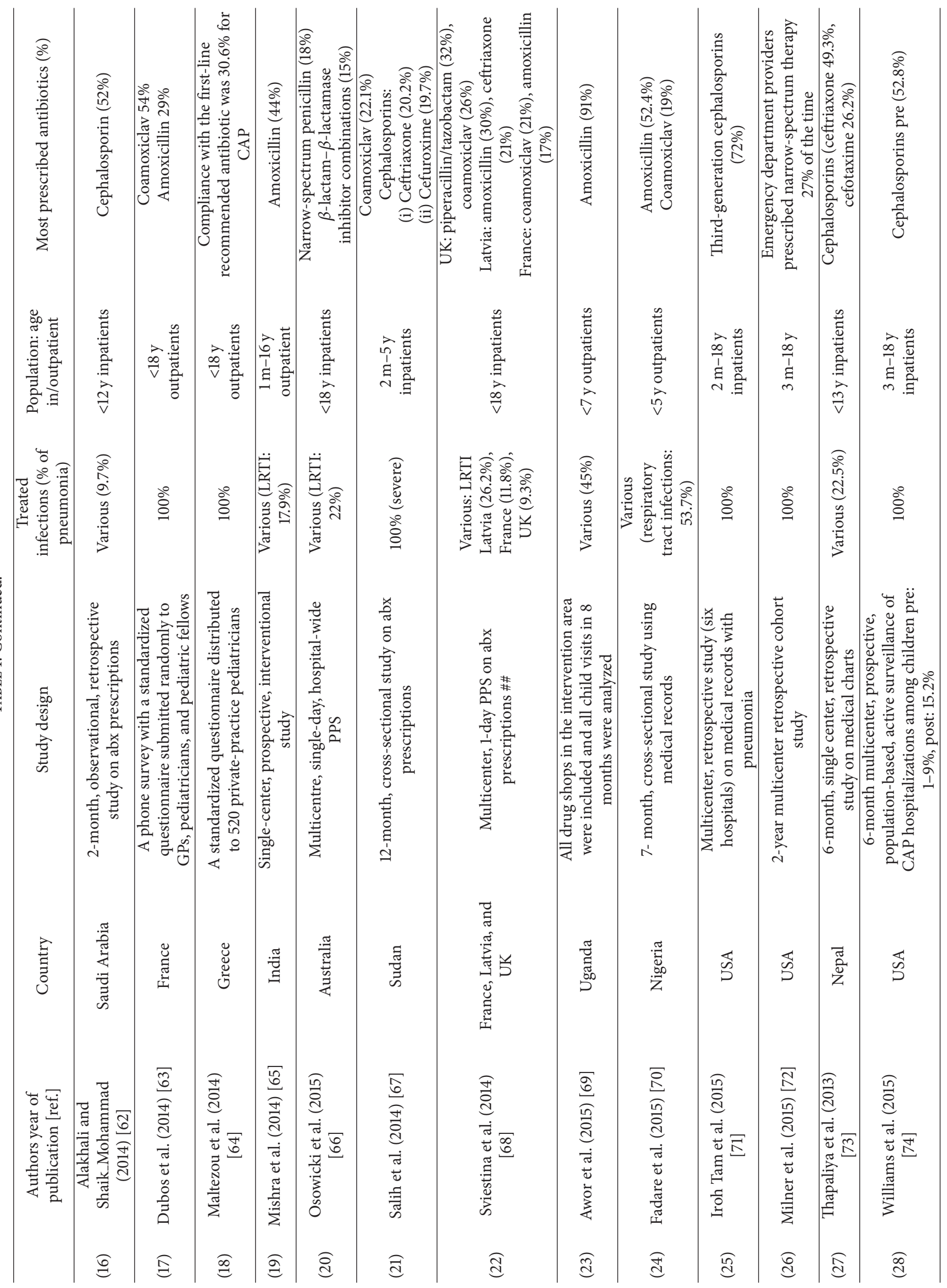




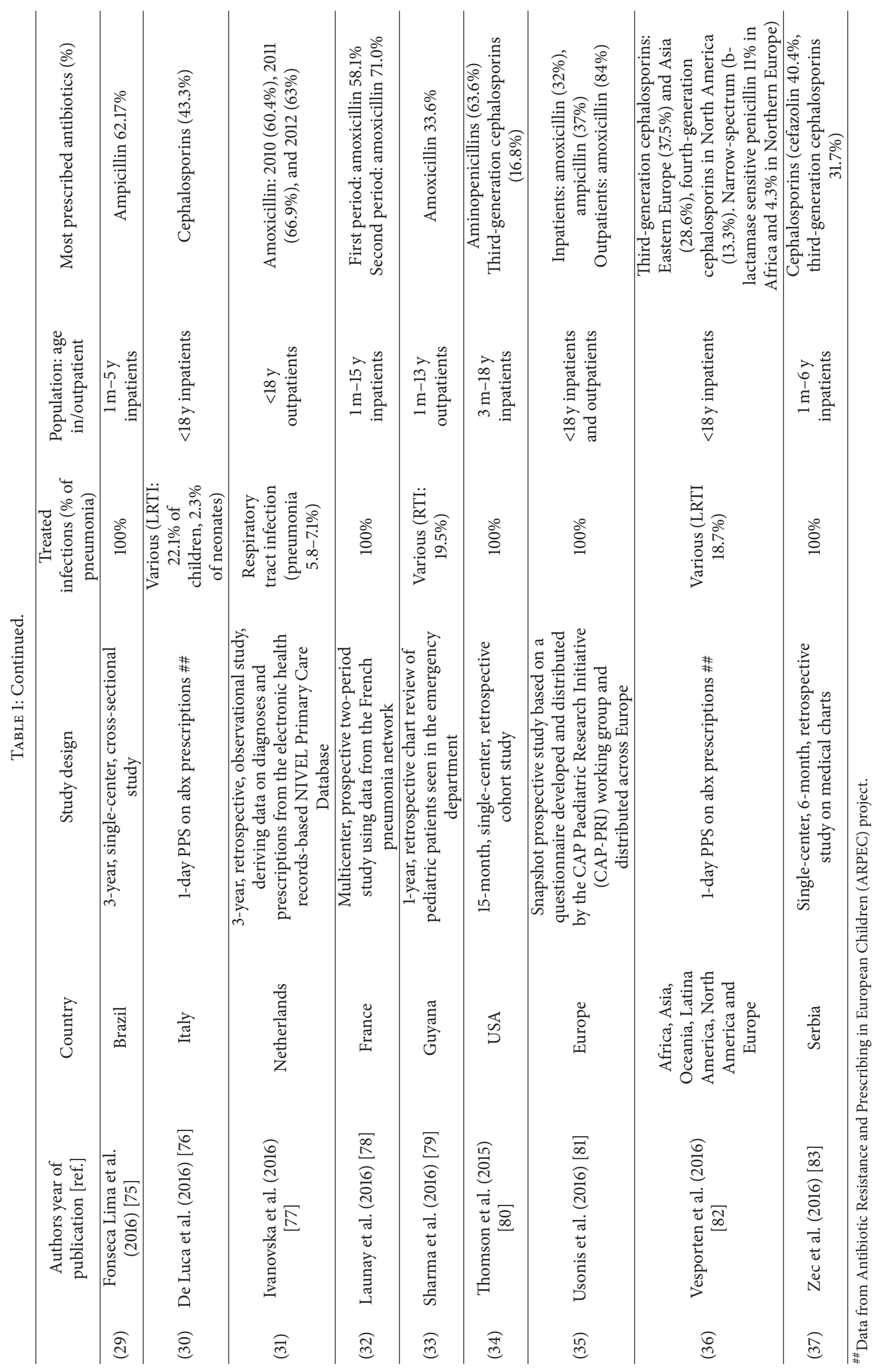


of cases) was the combination of amoxicillin/clavulanate [58]. Another prospective study by Moinuddin et al. was conducted over 9 months in 2012, in two hospitals in Bangalore. The most widely used therapy was amoxicillin + clavulanate $(43,8 \%)$, with third-generation cephalosporins as the most prescribed class (ceftriaxone $36.2 \%$, cefotaxime $21 \%)$. Penicillin in single therapy accounted only for $1 \%$ of prescriptions [57].

Cephalosporins were often reported to be the class with higher rates of prescription for CAP treatment, as reported by many centres in different countries, like Ethiopia [60], Saudi Arabia [62], Nepal [73], Serbia [83], Sudan [67], US [54, 71, 74], Italy [76], and other European countries [48, 82].

Feleke and colleagues conducted their 5-month prospective study in a large government hospital in Ethiopia. The study includes all children admitted in that period and CAP accounted for $56.3 \%$ of all drug prescriptions. Ceftriaxone was the most prescribed drug (43.5\%) followed by gentamicin (25.6\%), and penicillin and ampicillin ranked the third and fourth place [62]. In a retrospective study by $\mathrm{Zec}$ et al., during a 6-month period in 2014, first- and third-generation cephalosporins were given to children with CAP in $40.4 \%$ and $31.7 \%$ of cases, respectively. Penicillin was used in $25 \%$ of cases [83]. In an Italian 1-day point-prevalence survey on antimicrobial use in hospitalized neonates and children in 2012, the main indication for treatment in children was LRTI (34\%), with higher prevalence of third-generation cephalosporins (43.3\%) followed by macrolides accounting for $26.8 \%$. No ampicillin/amoxicillin prescription was reported [76].

Association of aminopenicillins was found to be often prescribed: amoxicillin + clavulanate was reported to be the most used therapy by studies conducted in Saudi Arabia [51], France [63], and India [58], and a study conducted in Iraq, by Younis, reported that ampicillin + cloxacillin, alone and in combination, accounted for $50 \%$ of the antibiotic prescriptions for the children with respiratory tract infections [50].

One study, in particular, reported a high rate of prescriptions of macrolides. It was conducted in Norway, by Fossum and colleagues, and included the prescriptions of general practitioners in case of respiratory tract infections in patients $<6$ years. They found that macrolides were prescribed in $44 \%$ of the cases of pneumonia, more than penicillin $\mathrm{V}$, which was used in $31 \%$, and that extended spectrum penicillin accounted for $24 \%$ of the prescriptions [55].

Studies on the appropriateness of prescriptions or prescriber behavior were also found. In addition to the aforementioned French study, Maltezou et al. showed how Greek private-practice pediatricians guidelines compliance is only around 30.6\% [64]. Moreover, Ceyhan et al., in a multicenter point-prevalence survey with respiratory infection as main diagnosis, showed how cephalosporins and penicillin (most of the time combined with b-lactamase inhibitors) were improperly prescribed in $36.1 \%$ and $43.7 \%$ of cases, respectively. These analyses highlighted how, even now, adherence to guidelines is still low. On the other hand, Usonis and colleagues through a questionnaire developed and distributed by the CAP Pediatric Research Initiative (CAP-PRI) working group and distributed across Europe showed high adherence to CAP guidelines, with a high prescription rate of narrowspectrum penicillin for inpatients (amoxicillin (32\%) and ampicillin (37\%)) and outpatients (amoxicillin (84\%)) [81].

An encouraging result is that almost a half (15/38) of the studies included in this review reported high rates of single therapy aminopenicillin or penicillin prescriptions. These studies were conducted in Brasil [75], Guyana [79], India [65], Mongolia [6], Nigeria [70], Tanzania [56], USA [80], Uganda [69], and France [78], showing that the current guidelines are applied in both developed and developing countries. The study by Awor et al. in Uganda in 2015 offers an important cause for reflection, since it shows that adherence to guidelines may be successfully implemented even in a nonhospital environment. In their 8-month quasiexperimental analysis, they investigated the visits and the prescriptions made by drug shop sellers, underlining how this class of health workers plays an important role in providing healthcare to populations in rural areas. Their result is that $91 \%$ of the children with pneumonia that were visited by drug shop sellers received amoxicillin, the highest rate of its prescription among all the studies included in this review [69].

Some data of antimicrobial prescriptions have been derived from point-prevalence surveys (PPS), including Australia [66, 82], Mexico, Colombia, Argentina, Singapore, and European countries [48, 49,81,82]. CAP was not the only analyzed disease, but the LRTI category was the most represented. Even though antimicrobial prescriptions were not specific only to CAP, PPS data were similar to the results of those other studies that were performed in the same country, but specifically designed for CAP.

Another interesting result is that the development of a local antimicrobial stewardship program could reduce inappropriate antimicrobial use and bacterial resistance, enhance patients' safety, and lower drug costs [84]. Moreover, global PPS could be a reliable and feasible tool for monitoring antimicrobial prescriptions all over the world.

Finally, it is also worthy of notice how data from certain countries were not available despite interest in the improvement of antibiotic prescription. For example, we did not find any report about pediatric CAP antibiotic treatment in Canada, even extending the research to 2005-2010. Likewise, we did not find any study set in other important countries, like China and Russia. It is worth remembering that the reduction of antimicrobial therapy and of microbial resistance is a global issue, and global effort is required in order to improve antibiotic prescription and administration practice.

\section{Conclusions}

In the last 10 years, many guidelines on the optimal treatment for childhood CAP have been published, with the aim of optimizing pediatric CAP antibiotic prescriptions. Our review demonstrates that the implementation of these guidelines is still limited but also that achieving the optimal prescription is possible and can be done in both developed and developing countries. 


\section{Abbreviations}

\begin{tabular}{|c|c|}
\hline CAP: & $\begin{array}{l}\text { Community-acquired } \\
\text { pneumonia }\end{array}$ \\
\hline RSV: & Respiratory syncytial virus \\
\hline $\mathrm{HiB}:$ & Type B Haemophilus influenzae \\
\hline PCV, PCV7, and PCV 13: & $\begin{array}{l}\text { Pneumococcal conjugate } \\
\text { vaccine }\end{array}$ \\
\hline MIC: & $\begin{array}{l}\text { Minimal inhibitory } \\
\text { concentration }\end{array}$ \\
\hline LRTI: & Lower respiratory tract infection \\
\hline MSSA: & $\begin{array}{l}\text { Methicillin-sensitive } \\
\text { Staphylococcus aureus }\end{array}$ \\
\hline MRSA: & $\begin{array}{l}\text { Methicillin-resistant } \\
\text { Staphylococcus aureus }\end{array}$ \\
\hline CA-MRSA: & $\begin{array}{l}\text { Community-acquired } \\
\text { methicillin-resistant } \\
\text { Staphylococcus aureus }\end{array}$ \\
\hline HAP: & Hospital-acquired pneumonia \\
\hline VAP: & $\begin{array}{l}\text { Ventilator-associated } \\
\text { pneumonia. }\end{array}$ \\
\hline
\end{tabular}

\section{Additional Points}

Availability of Data. The datasets used and/or analyzed during the current study are available from the corresponding author on reasonable request.

\section{Conflicts of Interest}

The authors declare that they have no conflicts of interest.

\section{References}

[1] C. L. Fischer Walker, I. Rudan, L. Liu et al., "Global burden of childhood pneumonia and diarrhoea," The Lancet, vol. 381, no. 9875, pp. 1405-1416, 2013.

[2] H. J. Zar, P. Jeena, A. Argent, R. Gie, and S. A. Madhi, "Working Groups of the Paediatric Assembly of the South African Thoracic Society. Diagnosis and management of communityacquired pneumonia in childhood-South African Thoracic Society Guidelines," South African Medical Journal, vol. 95, pp. 977-981, 2005.

[3] WHO, World Health Statistics. World Health Organization, 2015.

[4] L. Liu, H. Johnson, and S. Cousens, "Global, regional and national causes of child mortality: an update systematic analysis for 2010 with time trends since 2000," The Lancet, vol. 379, no. 9832, pp. 2151-2161, 2012.

[5] M. Don, M. Canciani, and M. Korppi, "Community-acquired pneumonia in children: What's old? What's new?" Acta Paediatrica, vol. 99, no. 11, pp. 1602-1608, 2010.

[6] G. Dorj, D. Hendrie, R. Parsons, and B. Sunderland, "An evaluation of prescribing practices for community-acquired pneumonia (CAP) in Mongolia," BMC Health Services Research, vol. 13, no. 1, 2013.

[7] M. Harris, J. Clark, N. Coote et al., "British Thoracic Society guidelines for the management of community acquired pneumonia in children: update 2011," Thorax, vol. 66, no. 2, pp. iilii23, 2011.
[8] I. C. Michelow, K. Olsen, J. Lozano et al., "Epidemiology and Clinical Characteristics of Community-Acquired Pneumonia in Hospitalized Children," Pediatrics, vol. 113, no. 4 I, pp. 701-707, 2004.

[9] A. G. Falade and A. I. Ayede, "Epidemiology, aetiology and management of childhood acute community-acquired pneumonia in developing countries-a review," African Journal of Medicine and Medical Sciences, vol. 40, no. 4, pp. 293-308, 2011.

[10] F. Shann, "Determining etiology of pneumonia," The Pediatric Infectious Disease Journal, vol. 14, no. 10, pp. 920-921, 1995.

[11] P. Drummond, J. Clark, A. Cant, J. Wheeler, A. Galloway, and R. Freeman, "Community acquired pneumonia - A prospective UK study," Archives of Disease in Childhood, vol. 83, no. 5, pp. 408-412, 2000.

[12] S. Jain, D. J. Williams, S. R. Arnold et al., "Community-acquired pneumonia requiring hospitalization among U.S. children," The New England Journal of Medicine, vol. 372, no. 9, pp. 835-845, 2015.

[13] J. S. Bradley, C. L. Byington, S. S. Shah et al., "The management of community-acquired pneumonia in infants and children older than 3 months of age: Clinical practice guidelines by the pediatric infectious diseases society and the infectious diseases society of America," Clinical Infectious Diseases, vol. 53, no. 7, pp. e25-e76, 2011.

[14] D. Greenberg, N. Givon-Lavi, S. Ben-Shimol, J. B. Ziv, and R. Dagan, "Impact of PCV7/PCV13 introduction on communityacquired alveolar pneumonia in children $<5$ years," Vaccine, vol. 33, no. 36, pp. 4623-4629, 2015.

[15] G. E. Lee, S. A. Lorch, S. Sheffler-Collins, M. P. Kronman, and S. S. Shah, "National hospitalization trends for pediatric pneumonia and associated complications," Pediatrics, vol. 126, no. 2, pp. 204-213, 2010.

[16] S. Esposito and N. Principi, "Pneumococcal vaccines and the prevention of community-acquired pneumonia," Pulmonary Pharmacology and Therapeutics, vol. 32, pp. 124-129, 2015.

[17] J. Hasegawa, M. Mori, S. Showa et al., "Pneumococcal vaccination reduced the risk of acute otitis media: Cohort study," Pediatrics International, vol. 57, no. 4, pp. 582-585, 2015.

[18] G. A. Tramper-Stranders, "Childhood community-acquired pneumonia: A review of etiology- and antimicrobial treatment studies," Paediatric Respiratory Reviews, 2017.

[19] E. Berti, L. Galli, M. De Martino, and E. Chiappini, "International guidelines on tackling community-acquired pneumonia show major discrepancies between developed and developing countries," Acta Paediatrica, vol. 102, no. 465, pp. 4-16, 2013.

[20] D. E. Low, M. E. Pichichero, and U. B. Schaad, "Optimizing Antibacterial Therapy for Community-Acquired Respiratory Tract Infections in Children in an Era of Bacterial Resistance," Clinical Pediatrics, vol. 43, no. 2, pp. 135-151, 2004.

[21] S. Esposito, L. Indinnimeo, M. Duse et al., "Diagnosis and treatment of community-acquired pneumonia in pediatric ageguidelines of the Italian Pediatric Societies (SIP, SITIP, SIMRI, SIAIP, SIPPS, SIMEUP)," Minerva Pediatrica, vol. 61, no. 6, pp. 887-890, 2009.

[22] H. J. Zar and T. W. Ferkol, "The global burden of respiratory disease - Impact on child health," Pediatric Pulmonology, vol. 49, no. 5, pp. 430-434, 2014.

[23] N. K. Arora, "Rational use of antibiotics for pneumonia: India Clinical Epidemiology Network (INDIACLEN) task force on pneumonia," Indian Pediatrics, vol. 47, no. 1, pp. 11-18, 2010. 
[24] M. P. Weinstein, K. P. Klugman, and R. N. Jones, "Rationale for Revised Penicillin Susceptibility Breakpoints versus Streptococcus pneumoniae: Coping with Antimicrobial Susceptibility in an Era of Resistance," Clinical Infectious Diseases, vol. 48, no. 11, pp. 1596-1600, 2009.

[25] M. A. Queen, A. L. Myers, M. Hall et al., "Comparative effectiveness of empiric antibiotics for community-acquired pneumonia," Pediatrics, vol. 133, no. 1, pp. e23-e29, 2014.

[26] W. A. Craig and D. Andes, "Pharmacokinetics and pharmacodynamics of antibiotics in otitis media," The Pediatric Infectious Disease Journal, vol. 15, no. 3, pp. 255-259, 1996.

[27] P. D. Lister, A. Pong, S. A. Chartrand, and C. C. Sanders, "Rationale behind high-dose amoxicillin therapy for acute otitis media due to penicillin-nonsusceptible pneumococci: support from in vitro pharmacodynamic studies," Antimicrobial Agents and Chemotherapy, vol. 41, no. 9, pp. 1926-1932, 1997.

[28] W. Fonseca, K. Hoppu, L. C. Rey, J. Amaral, and S. Qazi, "Comparing pharmacokinetics of amoxicillin given twice or three times per day to children older than 3 months with pneumonia," Antimicrobial Agents and Chemotherapy, vol. 47, no. 3, pp. 997-1001, 2003.

[29] P. I. Lee, C. H. Chiu, P. Y. Chen, C. Y. Lee, and T. Y. Lin, "Taiwan Pediatric Working Group for Guideline on the Management of CAP in Children. Guidelines for the management of community-acquired pneumonia in children," Acta Paediatr Taiwan, vol. 48, pp. 167-180, 2007.

[30] M. I. Ubeda Sansano, J. Murcia Garcia, and M. T. Asensi Monzo, Neumonia adquirida en la comunidad. Protocolos del GVR. Last update February 8, 2013, http://aepap.org/grupos/grupode-vias-respiratorias/protocolos-del-gvr.

[31] S. Awasthi, G. Agarwal, J. V. Singh et al., "Effectiveness of 3-day amoxycillin vs. 5-day co-trimoxazole in the treatment of nonsevere pneumonia in children aged 2-59 months of age: A multicentric open labeled trial," Journal of Tropical Pediatrics, vol. 54, no. 6, pp. 382-389, 2008.

[32] W. L. Straus, S. A. Qazi, Z. Kundi, N. K. Nomani, and B. Schwartz, "Antimicrobial resistance and clinical effectiveness of co-trimoxazole versus amoxycillin for pneumonia among children in Pakistan: Randomised controlled trial," The Lancet, vol. 352, no. 9124, pp. 270-274, 1998.

[33] CATCHUP Study Group, "Clinical efficacy of co-trimoxazole versus amoxicillin twice daily for treatment of pneumonia: A randomised controlled clinical trial in Pakistan," Archives of Diseases in Childhood, vol. 86, no. 2, pp. 113-118, 2002.

[34] P. Krishnan, P. Rajendran, A. P. Sambandan, C. Anitha, R. K. Chavda, and K. J. Khobragade, "Evaluation of coamoxiclav and other antibiotics against $\mathrm{S}$ pneumoniae and $\mathrm{H}$ influenzae from paediatric cases of acute respiratory infections," Journal of the Indian Medical Association, vol. 109, no. 4, pp. 241-244, 2011.

[35] G. Agarwal, S. Awasthi, S. K. Kabra, A. Kaul, S. Singhi, S. D. Walter et al., "Three day versus five day treatment with amoxicillin for non-severe pneumonia in young children: a multicentre randomised controlled trial," BMJ Journals, vol. 328, pp. 791-796, 2004.

[36] MASCOT Group, "Clinical efficacy of three day versus five days of oral amoxicillin for the treatment of childhood pneumonia: a multicenter randomised blind trial," The Lancet, vol. 360, no. 9336, pp. 835-841, 2002.

[37] R. Lodha, S. K. Kabra, and R. M. Pandey, "Antibiotics for community-acquired pneumonia in children," The Cochrane Database of Systematic Reviews, vol. 4, no. 6, 2013.
[38] M. R. Jacobs, C. E. Good, A. R. Windau et al., "Activity of ceftaroline against recent emerging serotypes of Streptococcus pneumoniae in the United States," Antimicrobial Agents and Chemotherapy, vol. 54, no. 6, pp. 2716-2719, 2010.

[39] S. Tristram, M. R. Jacobs, and P. C. Appelbaum, "Antimicrobial resistance in Haemophilus influenzae," Clinical Microbiology Reviews, vol. 20, no. 2, pp. 368-389, 2007.

[40] C. J. Harrison, C. Woods, G. Stout, B. Martin, and R. Selvarangan, "Susceptibilities of Haemophilus influenzae, Streptococcus pneumoniae, including serotype 19A, and Moraxella catarrhalis paediatric isolates from 2005 to 2007 to commonly used antibiotics," Journal of Antimicrobial Chemotherapy, vol. 63, no. 3, pp. 511-519, 2009.

[41] R. Pallares, O. Capdevila, J. Liñares et al., "The effect of cephalosporin resistance on mortality in adult patients with nonmeningeal systemic pneumococcal infections," American Journal of Medicine, vol. 113, no. 2, pp. 120-126, 2002.

[42] L. Ambroggio, M. Test, J. P. Metlay et al., "Beta-lactam versus beta- lactam/macrolide therapy in pediatric outpatient pneumonia," Pediatric Pulmonology, vol. 51, no. 5, pp. 541-548, 2016.

[43] E. Lappin and A. J. Ferguson, "Gram-positive toxic shock syndromes," The Lancet Infectious Diseases, vol. 9, no. 5, pp. 281290, 2009.

[44] D. Jeyaratnam, "Community associated MRSA: an alert to paediatricians," Archives of Disease in Childhood, vol. 91, no. 6, pp. 511-512, 2006.

[45] C. R. Woods, "Macrolide-Inducible Resistance to Clindamycin and the D-Test," The Pediatric Infectious Disease Journal, vol. 28, no. 12, pp. 1115-1118, 2009.

[46] R. G. Wunderink, M. S. Niederman, M. H. Kollef et al., "Linezolid in methicillin-resistant staphylococcus aureus nosocomial pneumonia: A randomized, controlled study," Clinical Infectious Diseases, vol. 54, no. 5, pp. 621-629, 2012.

[47] M. S. García, M. Á. De La Torre, G. Morales et al., "Clinical outbreak of linezolid-resistant Staphylococcus aureus in an intensive care unit," Journal of the American Medical Association, vol. 303, no. 22, pp. 2260-2264, 2010.

[48] B. Amadeo, P. Zarb, A. Muller et al., "European Surveillance of Antibiotic Consumption (ESAC) point prevalence survey 2008: Paediatric antimicrobial prescribing in 32 hospitals of 21 European countries," Journal of Antimicrobial Chemotherapy, vol. 65, no. 10, Article ID dkq309, pp. 2247-2252, 2010.

[49] M. Ceyhan, I. Yildirim, C. Ecevit et al., "Inappropriate antimicrobial use in Turkish pediatric hospitals: A multicenter point prevalence survey," International Journal of Infectious Diseases, vol. 14, no. 1, pp. e55-e61, 2010.

[50] A. I. Younis, "Trends in prescribing antibiotics for hospitalized children with respiratory tract infections in Mosul region," ThiQar Medical Journal, vol. 4, no. 4, pp. 101-104, 2010.

[51] K. A. Mohajer, S. M. Al-Yami, M. I. Al-Jeraisy, and M. A. Abolfotouh, "Antibiotic prescribing in a pediatric emergency setting in central Saudi Arabia," Saudi Medical Journal, vol. 32, no. 2, pp. 197-198, 2011.

[52] M. Bergicho, M. Mohammed, and N. Wabe, "Assessment of the pattern of drug prescribing in pediatrics ward in tertiary setting hospital in Addis Ababa, Ethiopia," Gaziantep Medical Journal, vol. 18, no. 2, pp. 61-65, 2012.

[53] C. Borrás Novell, S. Hernández Bou, and J. García García, "Prescripción antibiótica en los pacientes hospitalizados desde Urgencias. Estudio multicéntrico," Anales de Pediatría, vol. 79, no. 1, pp. 15-20, 2013. 
[54] T. V. Brogan, M. Hall, D. J. Williams et al., "Variability in Processes of Care and Outcomes among Children Hospitalized with Community-Acquired Pneumonia," The Pediatric Infectious Disease Journal, vol. 31, no. 10, pp. 1036-1041, 2012.

[55] G. H. Fossum, M. Lindbæk, S. Gjelstad, I. Dalen, and K. J. Kværner, "Are children carrying the burden of broad-spectrum antibiotics in general practice? Prescription pattern for paediatric outpatients with respiratory tract infections in Norway," BMJ Open, vol. 3, no. 1, article no. A23, 2013.

[56] J. J. Gwimile, S. A. Shekalaghe, G. N. Kapanda, and E. R. Kisanga, "Antibiotic prescribing practice in management of cough and/or diarrhoea in Moshi Municipality, Northern Tanzania: cross-sectional descriptive study," The Pan African Medical Journal, vol. 12, 2012.

[57] K. Moinuddin, M. A. Altaf, and K. Githa, "Study of prescribing pattern of antibiotic in pediatric patients with pneumonia," Journal of Applied Pharmaceutical Science, vol. 03, no. 04, pp. 606-613, 2012.

[58] D. K. Choudry and B. Bezbaruah, "Antibiotic prescriptions pattern in paediatric in-patient department gauhati medical college and hospital, Guwahati," Journal of Applied Pharmaceutical Science, vol. 3, no. 8, pp. 144-148, 2013.

[59] S. De Sà Del Fiol Fde, L. C. Lopes, S. Barberato-Filho, and C. Motta Cde, "Evaluation of the prescription and use of antibiotics in Brazilian children," Brazilian Journal of Infectious Diseases, vol. 17, no. 3, pp. 332-337, 2013.

[60] M. Feleke, W. Yenet, and J. Lenjisa, "Prescribing pattern of antibiotics in pediatric wards of Bishoftu Hospital, East Ethiopia," International Journal of Basic \& Clinical Pharmacology, vol. 2, no. 6, pp. 718-722, 2013.

[61] M. I. Neuman, S. S. Shah, D. J. Shapiro, and A. L. Hersh, "Emergency department management of childhood pneumonia in the United States prior to publication of national guidelines," Academic Emergency Medicine, vol. 20, no. 3, pp. 240-246, 2013.

[62] K. M. Alakhali and A. A. Shaik_Mohammad, "Prescribing Pattern of Antibiotics in Pediatric Patients in the Jazan Region, Kingdom of Saudi Arabia," Rajiv Gandhi University of Health Sciences Journal of Pharmaceutical Sciences, vol. 4, no. 3, pp. 120124, 2014.

[63] F. Dubos, C. Delvart, C. Mordacq et al., "Evaluation of ambulatory prescribing for community-acquired pneumonia in children," Archives de Pédiatrie, vol. 21, no. 8, pp. 827-833, 2014.

[64] H. C. Maltezou, P. Katerelos, H. Asimaki, E. Roilides, and M. Theodoridou, "Antibiotic prescription practices for common infections and knowledge about antibiotic costs by privatepractice pediatricians in Greece," Minerva Pediatrica, vol. 66, no. 3, pp. 209-216, 2014.

[65] H. Mishra, R. Mishra, and A. Mondal, "Prescription pattern of antimicrobial drugs in pediatrics outpatient department of a tertiary care teaching hospital of North India," International Journal of Basic \& Clinical Pharmacology, vol. 3, no. 2, pp. 385388, 2014.

[66] J. Osowicki, A. Gwee, J. Noronha et al., "Australia-wide point prevalence survey of antimicrobial prescribing in neonatal units: How much and how good?" The Pediatric Infectious Disease Journal, vol. 34, no. 8, pp. e185-e190, 2015.

[67] K. E. M. Salih, J. A. Bilal, M. A. Alfadeel et al., "Poor adherence to the world health organization guidelines of treatment of severe pneumonia in children at Khartoum, Sudan," BMC Research Notes, vol. 7, no. 1, article no. 531, 2014.

[68] I. Sviestina, J. Aston, M. Lorrot, and D. Mozgis, "A comparison of antibiotic use in three specialist paediatric hospitals in
France, Latvia and the UK," European Journal of Hospital Pharmacy: Science and Practice, vol. 22, no. 3, pp. 132-137, 2014.

[69] P. Awor, H. Wamani, T. Tylleskar, and S. Peterson, "Drug seller adherence to clinical protocols with integrated management of malaria, pneumonia and diarrhoea at drug shops in Uganda," Malaria Journal, vol. 14, no. 1, article no. 277, 2015.

[70] J. Fadare, O. Olatunya, O. Oluwayemi, and O. Ogundare, "Drug prescribing pattern for under-fives in a paediatric clinic in South-Western Nigeria," Ethiop J Health Sci, vol. 25, no. 1, Article ID 25733787, p. 73, Jan 2015.

[71] P. Y. Iroh Tam, B. R. Hanisch, and M. O'Connell, “The Impact of Adherence to Pediatric Community-Acquired Pneumonia Guidelines on Clinical Outcomes," Clinical Pediatrics, vol. 54, no. 10, pp. 1006-1008, 2015.

[72] T. L. Milner, R. McCulloh, M. Koster, E. Biondi, V. Hill, and S. Ralston, "Antibiotic Prescribing Patterns Across the Continuum of Care for Children Hospitalized With Community-Acquired Pneumonia," Pediatric Emergency Care, 2015.

[73] K. Thapaliya, S. Shrestha, S. Bhattarai, D. Basnet, and R. K. Chaudhary, "Prescribing pattern of antibiotics in pediatric hospital in chitwan district in nepal," Journal of Applied Pharmaceutical Science, vol. 3, no. 8, pp. 144-148, 2013.

[74] D. J. Williams, K. M. Edwards, W. H. Self et al., "Antibiotic choice for children hospitalized with pneumonia and adherence to national guidelines," Pediatrics, vol. 136, no. 1, pp. 44-52, 2015.

[75] E. Fonseca Lima, D. Lima, G. H. Serra, M. A. Abreu e Lima, and M. J. Mello, "Prescription of antibiotics in communityacquired pneumonia in children: are we following the recommendations?" Therapeutics and Clinical Risk Management, vol. 12, pp. 983-988, 2016.

[76] M. De Luca, D. Donà, C. Montagnani et al., "Antibiotic prescriptions and prophylaxis in Italian children. Is it time to change? Data from the ARPEC project," PLoS ONE, vol. 11, no. 5, Article ID e0154662, 2016.

[77] V. Ivanovska, K. Hek, A. K. M. Teeuwisse, H. G. M. Leufkens, M. M. J. Nielen, and L. Van Dijk, "Antibiotic prescribing for children in primary care and adherence to treatment guidelines," Journal of Antimicrobial Chemotherapy, vol. 71, no. 6, pp. 1707$1714,2016$.

[78] E. Launay, K. Levieux, C. Levy et al., "Compliance with the current recommendations for prescribing antibiotics for paediatric community-acquired pneumonia is improving: Data from a prospective study in a French network," BMC Pediatrics, vol. 16, no. 1, article no. 126, 2016.

[79] S. Sharma, C. Bowman, B. Alladin-Karan, and N. Singh, "Antibiotic prescribing patterns in the pediatric emergency department at Georgetown Public Hospital Corporation: a retrospective chart review," BMC Infectious Diseases, vol. 16, no. 1, 2016.

[80] J. Thomson, L. Ambroggio, E. Murtagh Kurowski et al., "Hospital outcomes associated with guideline-recommended antibiotic therapy for pediatric pneumonia," Journal of Hospital Medicine, vol. 10, no. 1, pp. 13-18, 2015.

[81] V. Usonis, R. Ivaskevicius, J. Diez-Domingo et al., "Comparison between diagnosis and treatment of community-acquired pneumonia in children in various medical centres across Europe with the United States, United Kingdom and the World Health Organization guidelines," Pneumonia, vol. 8, no. 1, 2016.

[82] A. Versporten, J. Bielicki, N. Drapier, M. Sharland, and H. Goossens, "The Worldwide Antibiotic Resistance and Prescribing in European Children (ARPEC) point prevalence survey: developing hospital-quality indicators of antibiotic prescribing 
for children," Journal of Antimicrobial Chemotherapy, vol. 71, no. 4, pp. 1106-1117, 2016.

[83] S. Zec, K. Selmanovic, N. Andrijic, A. Kadic, L. Zecevic, and a. Zunic, "Evaluation of Drug Treatment of Bronchopneumonia at the Pediatric Clinic in Sarajevo," Medical Archives, vol. 70, no. 3, pp. 177-181, 2016.

[84] T. H. Dellit, R. C. Owens, J. E. McGowan Jr. et al., "Infectious Diseases Society of America and the Society for Healthcare Epidemiology of America guidelines for developing an institutional program to enhance antimicrobial stewardship," Clinical Infectious Diseases, vol. 44, no. 2, pp. 159-177, 2007. 


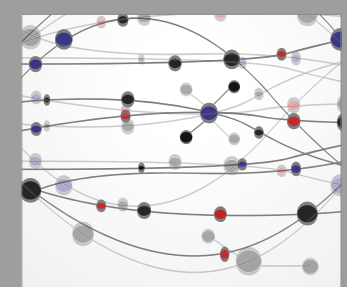

The Scientific World Journal
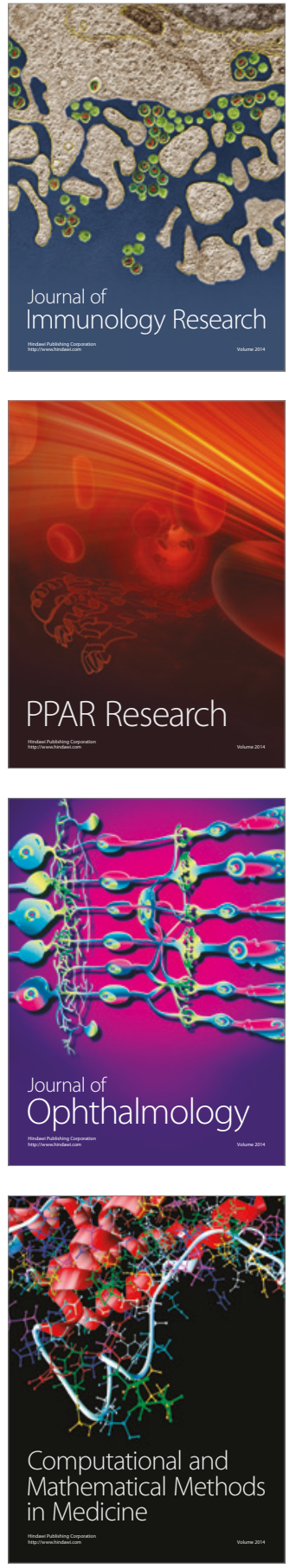

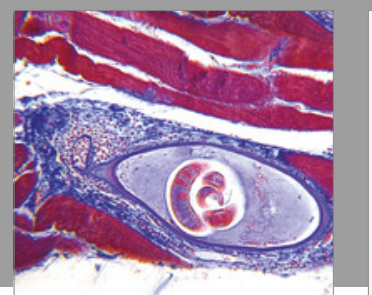

Gastroenterology Research and Practice
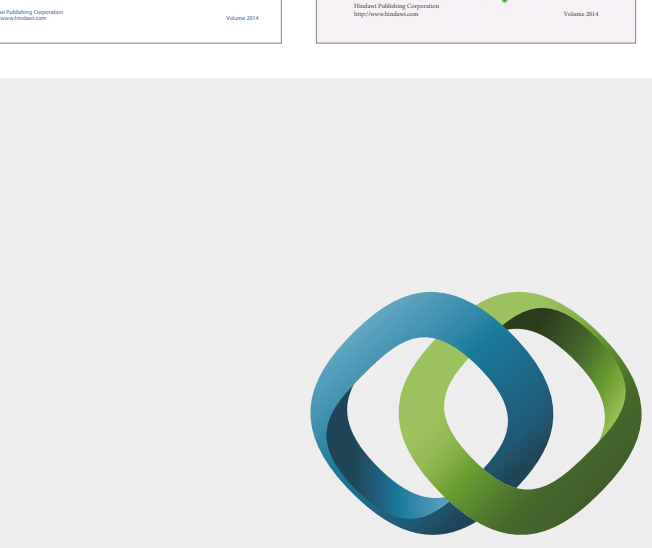

\section{Hindawi}

Submit your manuscripts at

https://www.hindawi.com
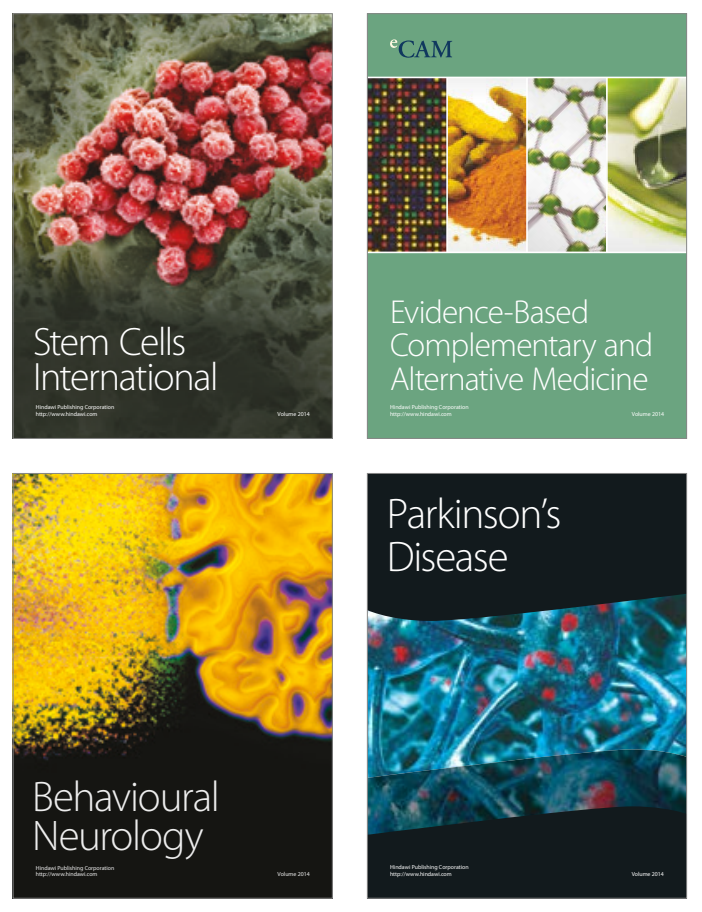
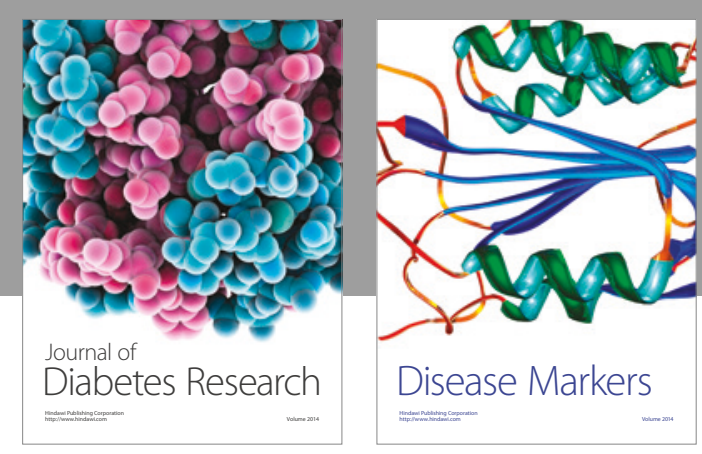

Disease Markers
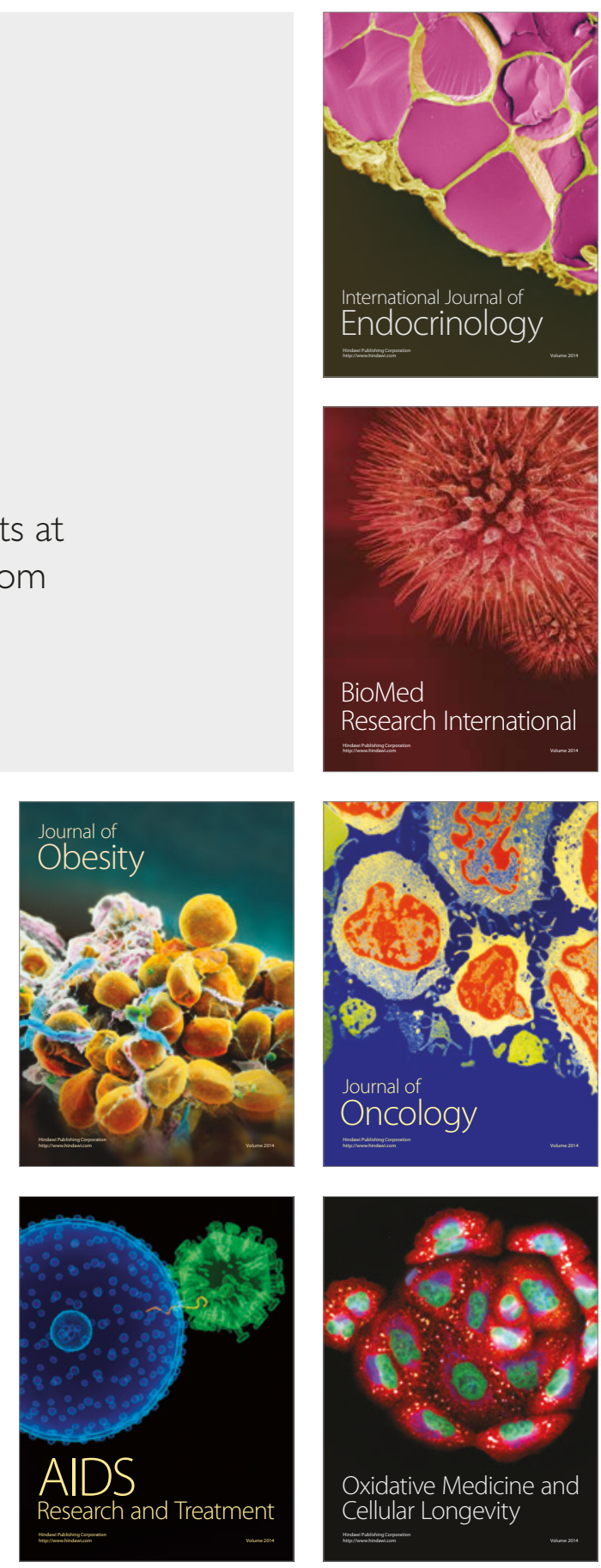